\title{
Molecular Characteristics of Escherichia coli Causing Bloodstream Infections During 20I0-20I5 in a Tertiary Hospital, Shanghai, China
}

\author{
Dan $\mathrm{Li}^{1,2, *}$ \\ Pei Li ${ }^{1,2, *}$ \\ Xiaoyan $\mathrm{Yu}^{3, *}$ \\ Xuefei Zhang ${ }^{1,2}$ \\ Qinglan Guo ${ }^{1,2}$ \\ Xiaogang $X u^{1,2}$ \\ Minggui Wang ${ }^{1,2}$ \\ Minghua Wang ${ }^{1,2}$ \\ 'Institute of Antibiotics, Huashan \\ Hospital, Fudan University, Shanghai, \\ People's Republic of China; ${ }^{2} \mathrm{Key}$ \\ Laboratory of Clinical Pharmacology of \\ Antibiotics, Ministry of Health, Shanghai, \\ People's Republic of China; ${ }^{3}$ Department \\ of Critical Care Medicine, Huashan \\ Hospital, Fudan University, Shanghai, \\ People's Republic of China
}

*These authors contributed equally to this work
Correspondence: Minghua Wang Institute of Antibiotics, Huashan Hospital, Fudan University, No. 12 Middle Wulumuqi Road, Shanghai, 200040,

People's Republic of China

$\mathrm{Tel}+8602152888193$

Email mhwang00Ister@I26.com
Background: The bloodstream infections (BSI) caused by Escherichia coli pose a serious threat to human health. To explore molecular characteristics of $E$. coli causing BSI, we collected E. coli isolates causing BSI in Huashan Hospital, Shanghai, China during 2010-2015.

Methods: In all E. coli isolates causing BSI collected from this study, polymerase chain reaction (PCR) was used to detect ESBLs and carbapenemase genes, and minimum inhibitory concentrations (MICs) were determined with agar dilution method. Outer membrane proteins were examined by SDS-PAGE in carbapenem-resistant strains. The genetic background of bla $a_{\mathrm{KPC}}$ gene was investigated by combining next-generation sequencing with a PCR mapping approach. Conjugation and transformation experiments were performed to verify the mobilization of $b l a_{\mathrm{KPC}}$. The transcription levels of the $b l a_{\mathrm{KPC}}$ gene were measured by RT-PCR.

Results: During 2010-2015, a total of 207 E. coli BSI strains were isolated. The positive rates of $\beta$-lactamase resistant genes were $0.48 \%$ (bla $\left.a_{\mathrm{KPC}}\right), 57 \%$ (bla $\left.a_{\mathrm{TEM}}\right), 23.67 \%$ $\left(b l a_{\mathrm{CTX}-\mathrm{M}-1}\right), 18.84 \%$ (bla $\left.a_{\mathrm{CTX}-\mathrm{M}-9}\right)$, and $1.93 \%$ (bla $\left.a_{\mathrm{SHV}}\right)$. High rates of $b l a_{\mathrm{TEM}}, b_{\text {CTX-M-1 }}$, and $b l a_{\mathrm{CTX}-\mathrm{M}-9}$ were consistent with the poor activity of third-generation cephalosporins and aztreonam in vitro, except for carbapenem and $\beta$-lactamase inhibitor combinations. Low susceptibility rates were observed for piperacillin $(25.1 \%)$ in contrast to the increased susceptibility when combined with $\beta$-lactamase inhibitors, namely piperacillin-tazobactam (90.8\%). Only one KPC-producing E. coli strain was detected. Despite the combination of OmpC loss, the low expression level of KPC may be responsible for its lower resistance to carbapenems compared to E. coli DH5 $\alpha$ (pKP12-100).

Conclusion: $E$. coli strains isolated from BSI were still highly susceptible to carbapenems and $\beta$-lactamase inhibitor combinations, and $b l a_{\text {СTX-M }}$ was the dominant genotype of ESBLs. The low expression of $b l a_{\mathrm{KPC}}$ may be the reason for the low resistance to carbapenems.

Keywords: Escherichia coli, bloodstream infections, resistance mechanism, ESBLs

\section{Introduction}

Escherichia coli, a gram-negative, motile, facultative anaerobic, rod-shaped bacterium, is one of the most common hospital-acquired pathogens which could cause urinary tract infections, abdominal infections, bloodstream infections (BSI), etc. ${ }^{1}$ Bacteremia represents a major cause of death with large increases in incidence and mortality. $^{2} E$. coli is a leading cause of bloodstream infection, it ranks first as a cause of community-acquired episodes and second as a cause of hospital-acquired BSI in different world regions. ${ }^{3}$ In addition, the incidence of $E$. coli BSI is increasing with associated high morbidity and mortality. ${ }^{4}$ In a study from 
England, all-cause mortality rate in individuals with $E$. coli bacteremia was $18.2 \% .^{5}$ And in China, one study showed that in 45 episodes of E. coli bacteremia, the 30-day allcause mortality was $22.2 \%{ }^{6}$

$\beta$-lactams are commonly used in the treatment of BSI caused by E. coli. $\beta$-lactamase production remains the most important contributing factor to $\beta$-lactam resistance. $^{7}$ Extended-spectrum $\beta$ lactamases (ESBLs), one group of $\beta$ lactamases, have the ability to hydrolyze and cause resistance to various types of the $\beta$-lactam antibiotics, including the third-generation cephalosporins and monobactams except the cephamycins and carbapenems. ${ }^{8,9}$ The most common ESBLs belong to three groups: TEM, SHV, and CTX-M types. ${ }^{8}$ The CTXM $\beta$ lactamases, now exceeding 50 different types, can be divided into five groups based on their amino acid identities: CTX-M-1, CTX-M-2, CTX-M-8, CTX-M-9, and CTX-M-25. ${ }^{10}$ Since their first description, class A extended-spectrum $\beta$-lactamases (ESBLs) producing E. coli continue to thwart our best clinical efforts. ESBLsproducing $E$. coli remains an important reason for therapy failure with cephalosporins and have serious consequences for infection control. ${ }^{7}$

Based on data from a multicenter randomized controlled trial, carbapenem is recommended as first-line treatment for infections outside of the urinary tract caused by ESBLs-producing E. coli. ${ }^{11}$ In E. coli, carbapenem resistance is typically caused by two main mechanisms: production of carbapenemases and $\beta$ lactamase activity combined with structural mutations. ${ }^{12}$ When combined with the mutation of outer membrane proteins or drug efflux pumps, ESBLs and AmpC are capable of conferring carbapenem resistance. ${ }^{12}$ According to the Ambler classification method, carbapenemases are members of the molecular class A, B, and D beta-lactamases. Class A and D enzymes have a serine-based hydrolytic mechanism, while class B enzymes are metallo-beta-lactamases that contain zinc in the active site. ${ }^{13,14}$ Of these, the KPC carbapenemases are the most prevalent, found mostly on plasmids in Klebsiella pneumoniae. ${ }^{15}$

Given the increasing importance and the fact that BSI caused by ESBLs-producing $E$. coli are an increasing therapeutic challenge, we investigated the molecular characteristics and antimicrobial susceptibility profiles of BSI caused by E. coli during 2010-2015 in Huashan Hospital, Shanghai, China.

\section{Materials and Methods}

\section{Sources of Strains}

A total of 207 non-duplicate E. coli isolates were collected from blood cultures of the inpatients of Huashan Hospital, Fudan University from 2010 to 2015. E. coli was identified using the Vitek 2 system. E. coli A49, selected from 207 strains mentioned previously, was used as the positive reference for outer membrane proteins with complete OmpC, OmpF, and OmpA. Plasmid pKP12-100 (Supplementary Data 1) was extracted from KPC-producing K. pneumoniae KP100-12 isolated from Huashan Hospital, not belonging to the 207 strains mentioned previously. This plasmid was used for transformation.

\section{MIC Determination}

In 207 E. coli strains in this study (Supplementary Data 2), minimum inhibitory concentrations (MICs) of cefotaxime, cefepime, ceftazidime, cefoxitin, ampicillin, aztreonam, piperacillin, piperacillin-tazobactam, meropenem, imipenem, ertapenem, fosfomycin, ciprofloxacin, amikacin, and gentamicin were determined with agar dilution method according to Clinical and Laboratory Standards Institute (CLSI) guidelines. Escherichia coli ATCC25922 and Pseudomonas aeruginosa ATCC27853 were used as routine controls for agents mentioned previously. The criterion of the susceptibility of fosfomycin was based on EUCAST (European Committee on Antimicrobial Susceptibility Testing) (Resistance standard: MIC $\geq$ $32 \mu \mathrm{g} / \mathrm{mL}$ ). We investigated the effect of efflux pump inhibitors cyanide 3-chlorophenylhydrazone (CCCP) on the carbapenems' susceptibility in the carbapenem-resistant E. coli. The concentration of CCCP was $25 \mu \mathrm{g} / \mathrm{mL}$.

\section{Detection of Resistance Genes}

Polymerase chain reaction (PCR) was used to detect $\beta$ lactmase such as bla $a_{\mathrm{TEM}}, \quad b l a_{\mathrm{CTX}-\mathrm{M}-1}, \quad b l a_{\mathrm{CTX}-\mathrm{M}-9}$, $b l a_{\mathrm{CTX}-\mathrm{M}-2}, b l a_{\mathrm{CTX}-\mathrm{M}-8}, b l a_{\mathrm{CTX}-\mathrm{M}-25}, b l a_{\mathrm{SHV}}$ and the carbapenemases genes such as $b l a_{\mathrm{KPC}}, b l a_{\mathrm{NDM}}, b l a_{\mathrm{IMP}} b l a_{\mathrm{SPM}}$, bla $_{\mathrm{AIM}}, b l a_{\mathrm{VIM}}, b l a_{\mathrm{OXA}}, b l a_{\mathrm{GIM}}, b l a_{\mathrm{BIC}}, b l a_{\mathrm{SIM}}, b l a_{\mathrm{DIM}}{ }^{16}$ And in our laboratory, we possessed isolates which were used as positive controls for the following genes: $b l a_{\mathrm{KPC}}$, $b l a_{\mathrm{NDM}}, b l a_{\mathrm{IMP}}, b l a_{\mathrm{OXA}}, b l a_{\mathrm{CTX}-\mathrm{M}-1}, b l a_{\mathrm{CTX}-\mathrm{M}-9}, b l a_{\mathrm{SHV}}$ and $b_{\text {TEM. }}$. Amplification was carried out as follows: initial denaturation at $94^{\circ} \mathrm{C}$ for $5 \mathrm{~min} ; 30$ cycles of $94^{\circ} \mathrm{C}$ for $30 \mathrm{~s}$, $60^{\circ} \mathrm{C}$ for $30 \mathrm{~s}$ and $72^{\circ} \mathrm{C}$ for $1 \mathrm{~min}$; and a final elongation step at $72^{\circ} \mathrm{C}$ for $7 \mathrm{~min}$. Primers were listed in Supplementary Data 3. 


\section{Analysis of Outer Membrane Proteins (OMPs) of KPC-Producing Strain}

Briefly, the suspension was sonicated on ice for about 10 minutes (60 cycles for 5 seconds with 5 -second intervals). The cell extracts were centrifuged at $15,600 \mathrm{~g} 4^{\circ} \mathrm{C}$ for 60 minutes, then we removed the supernatant and added 200 $\mu \mathrm{L} 1 \times \mathrm{PBS}, 25 \mu \mathrm{L} 10 \%$ Sarcosyl to resolve the protein. We repeated the procedure and suspended the OMP with 80 $\mu \mathrm{L} 1 \times$ PBS. Porins were loaded onto $15 \%$ SDSpolyacrylamide gel. After a 150-min electrophoresis of $80 \mathrm{~V}$, the membrane was stained with $0.1 \%$ Coomassie brilliant blue (Beyotime, China). ${ }^{17}$

\section{Conjugation and Transformation Experiments}

Conjugation and transformation experiments were performed to verify the transferability of $b l a_{\mathrm{KPC}}$. Plasmid pKP12-100 was extracted from a bla $a_{\mathrm{KPC}}$-positive isolate through phenol-chloroform method and then transformed into the recipient strain E. coli DH5 $\alpha$. E. coli J53, an azide-resistant strain was used for conjugation experiments. $^{18}$ Agar plate containing ampicillin $(50 \mu \mathrm{g} / \mathrm{mL})$ was used to screen for transformants. Conjugation strain was selected on LB agar plates supplemented with $50 \mu \mathrm{g} / \mathrm{mL}$ ampicillin and $150 \mu \mathrm{g} / \mathrm{mL}$ sodium azide. PCR with primers Kpc-RT (listed in Table 1) and sequencing were used to verify transformants and conjugation strain.

\section{Genetic Environment of bla $a_{\mathrm{KPC}}$ Positive Strain}

DNA was extracted from EC-A59 (TIANamp Bacteria DNA Kit) and next-generation sequencing was performed (Supplementary Data 4). Flanking sequences of

Table I Primers Presented Below Were Used for RT-qPCR of bla $a_{\mathrm{KPC}}$ Gene in This Study

\begin{tabular}{|l|l|c|}
\hline Primer & Direction & \multicolumn{1}{c|}{ Sequence $\left(\mathbf{5}^{\prime} \rightarrow \mathbf{3}^{\prime} \mathbf{)}\right.$} \\
\hline$m d h$ & $\begin{array}{l}\text { Forward } \\
\text { Reverse }\end{array}$ & $\begin{array}{c}\text { TGGCAAACTGAAACGGATA } \\
\text { ACGGCTGGATTGATGAAC }\end{array}$ \\
\hline Kpc-RT & $\begin{array}{l}\text { Forward } \\
\text { Reverse }\end{array}$ & $\begin{array}{l}\text { GAACCTGCGGAGTGTATG } \\
\text { TGTGCTTGTCATCCTTGTT }\end{array}$ \\
\hline Kpc-UP & $\begin{array}{l}\text { Forward } \\
\text { Reverse }\end{array}$ & $\begin{array}{l}\text { TGGCAAACTGAAACGGATA } \\
\text { ACGGCTGGATTGATGAAC }\end{array}$ \\
\hline
\end{tabular}

bla $a_{\mathrm{KPC}}$ were extracted from the contig harboring $b l a_{\mathrm{KPC}}$ and analyzed by Blastn. The genetic background of bla $a_{\mathrm{KPC}}$ gene in E. coli A59 obtained from this study was investigated by combining nextgeneration sequencing with a PCR mapping approach with the primers listed in Table 1 . We obtained the genetic background of $b l a_{\mathrm{KPC}}$ gene in E. coli A59 for further visualized genetic environment comparisons of $b l a_{\mathrm{KPC}}$-positive strains with Easyfig.

\section{Reverse Transcription-Quantitative PCR}

Total RNAs from clinical isolates were extracted using TaKaRa MiniBEST Universal RNA Extraction Kit and cDNA synthesis was performed with PrimeScript ${ }^{\mathrm{TM}}$ RT reagent Kit with gDNA Eraser (TaKaRa). The transcription levels of the $b l a_{\mathrm{KPC}}$ gene were measured with FastStart Universal SYBR Green Master (ROX)(Roche) as recommended by the manufacturers. The $m d h$ housekeeping gene was used as the internal reference. Primer sequences are listed in Table 1.

\section{Results \\ Molecular Characteristics of 207 E. coli Isolates Causing BSI}

During 2010 to 2015, a total of 207 E. coli isolates causing BSI were collected. The overall E. coli isolates causing BSI is on the rise, especially in 2015 (Figure 1). The antibiotic resistance rates were listed as follows: $67.1 \%$ (cefotaxime), $36.2 \%$ (cefepime), $42.5 \%$ (ceftazidime), 24.2\% (cefoxitin), 87.4\% (ampicillin), $45.9 \%$ (aztreonam), 59.9\% (piperacillin), 5.8\% (piperacillin-tazobactam), $0 \%$ (meropenem) and $0 \%$ (imipenem), 5.3\% (ertapenem), 19.8\% (fosfomycin), 76.8\% (ciprofloxacin), 9.2\% (amikacin), 61.4\% (gentamicin) (Table 2). Low susceptibility rates were observed for piperacillin $(25.1 \%)$ in contrast to increased susceptibility when combined with $\beta$-lactamase inhibitors, namely piperacillin-tazobactam $(90.8 \%)$.

The positive rates of $\beta$-lactamase resistant genes were $\quad 0.48 \% \quad\left(b l a_{\mathrm{KPC}}\right), \quad 57 \% \quad\left(b l a_{\mathrm{TEM}}\right), \quad 23.67 \%$ (bla $\left.a_{\mathrm{CTX}-\mathrm{M}-1}\right), \quad 18.84 \% \quad\left(b l a_{\mathrm{CTX}-\mathrm{M}-9}\right), \quad 1.93 \% \quad\left(b l a_{\mathrm{SHV}}\right)$. The rates of bla $a_{\text {ESBLs }}$ by year were shown in Figure 2. The most common $b l a_{\text {ESBLs }}$ was $b l a_{\text {CTX-M-1 }}$, followed

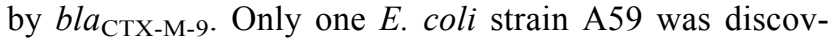
ered harboring $b l a_{\mathrm{KPC}-2}$ gene. Genes $b l a_{\mathrm{CTX}-\mathrm{M}-2}$, $b l a_{\mathrm{CTX}-\mathrm{M}-8}, b l a_{\mathrm{CTX}-\mathrm{M}-25}$ and $b l a_{\mathrm{NDM}}, b l a_{\mathrm{IMP}}, b l a_{\mathrm{SPM}}$, 


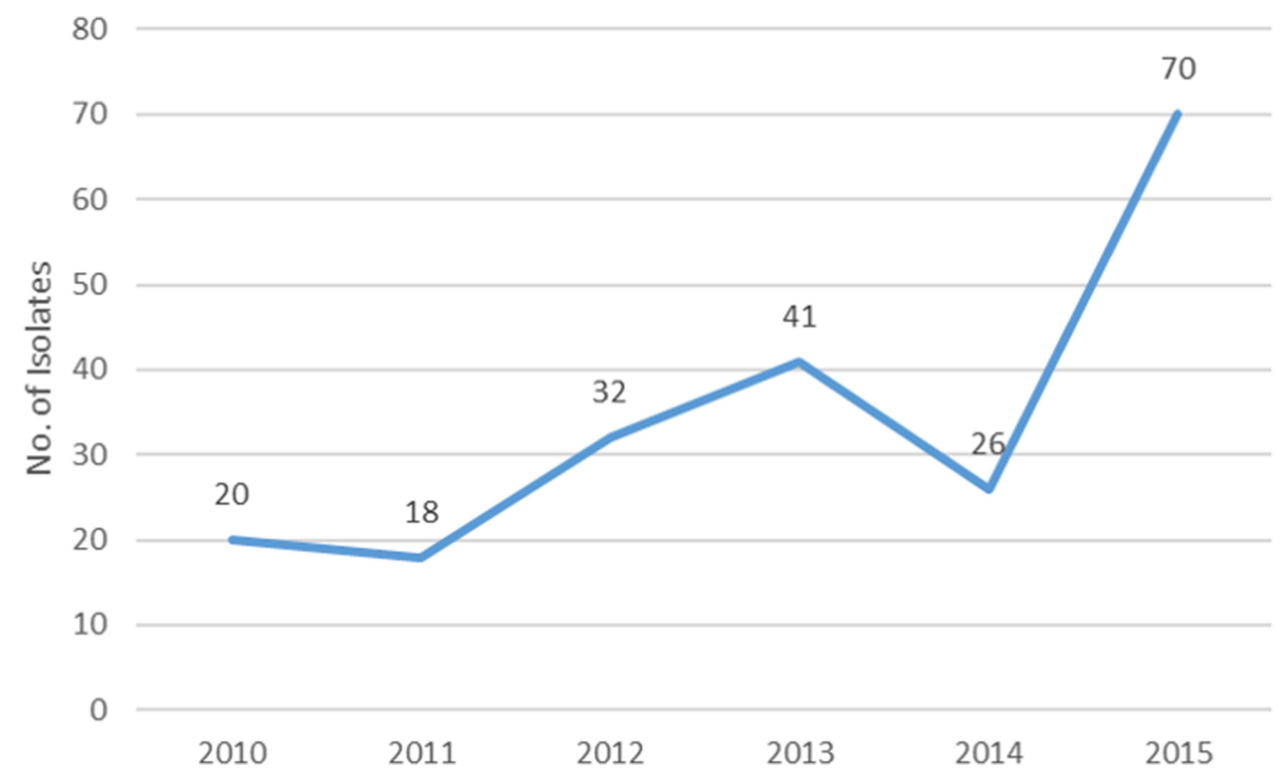

Figure I The isolation numbers of Escherichia coli causing bloodstream infections according to the year.

bla $a_{\mathrm{AIM}}, b l a_{\mathrm{VIM}}, b l a_{\mathrm{OXA}}, b l a_{\mathrm{GIM}}, b l a_{\mathrm{BIC}}, b l a_{\mathrm{SIM}}, b l a_{\mathrm{DIM}}$ were not detected in this study.

\section{OMP Profile of bla $a_{\mathrm{KPC}-\text { Positive Strain }}$}

SDS-PAGE analysis revealed different OMP profiles among the two isolates (Figure 3). OmpC loss was observed in isolate E. coli A59 compared to E. coli A49.
Conjugation and Transformation Experiments of the bla $a_{\mathrm{KPC}}$ Positive Strain The $b l a_{\mathrm{KPC}-2}$-carrying plasmid named pKP12-100 was extracted from K. pneumoniae $12-100$ and transformed into $E$. coli $\mathrm{DH} 5 \alpha$. The MIC of the transformant $E$. coli $\mathrm{DH} 5 \alpha$ (pKP12-100) can be seen in Table 3. Conjugation and transformation of $E$. coli $\mathrm{A} 59$ were failed with at least three repeats.

Table 2 Antimicrobial Susceptibility of Escherichia coli

\begin{tabular}{|c|c|c|c|c|c|c|c|c|c|}
\hline \multirow[t]{2}{*}{ Antimicrobial Agents } & \multicolumn{3}{|c|}{ Breakpoint (ug/mL) } & \multicolumn{3}{|c|}{ MIC (ug/mL) } & \multicolumn{3}{|c|}{ Number (\%) of Isolates } \\
\hline & $\mathbf{S}$ & $\mathbf{I}$ & $\mathbf{R}$ & Range & MIC50 & MIC90 & $\mathbf{R}$ & $\mathbf{I}$ & $\mathbf{S}$ \\
\hline Amikacin & $\leq 16$ & 32 & $\geq 64$ & $2 \sim>128$ & 4 & 16 & $19(9.2)$ & 0 & $188(90.8)$ \\
\hline Gentamicin & $\leq 4$ & 8 & $\geq 16$ & $0.5 \sim>128$ & 64 & $>128$ & $127(6 \mid .4)$ & $2(0.97)$ & 78(37.7) \\
\hline Cefotaxime & $\leq 1$ & 2 & $\geq 4$ & $<0.06 \sim>128$ & 64 & $>128$ & $139(67.1)$ & $2(0.97)$ & $66(31.9)$ \\
\hline Fosfomycin & $<32$ & - & $\geq 32$ & $0.25 \sim>128$ & I & $>128$ & $41(19.8)$ & - & $166(80.2)$ \\
\hline Cefepime & $\leq 2$ & 4-8 (SDD) & $\geq 16$ & $<0.06 \sim>128$ & 4 & 128 & $75(36.2)$ & $43(20.8)$ & $89(43.0)$ \\
\hline Ceftazidime & $\leq 4$ & 8 & $\geq 16$ & $0.125 \sim>128$ & 4 & 128 & $88(42.5)$ & $\mathrm{II}(5.3)$ & $108(52.2)$ \\
\hline Cefoxitin & $\leq 8$ & 16 & $\geq 32$ & $1 \sim>128$ & 8 & 128 & $50(24.2)$ & $18(8.7)$ & $139(67.1)$ \\
\hline Ciprofloxacin & $\leq 0.25$ & 0.5 & $\geq 1$ & $<0.06 \sim>128$ & 16 & 128 & 159(76.8) & $16(7.7)$ & $32(15.5)$ \\
\hline Ampicillin & $\leq 8$ & 16 & $\geq 32$ & $2 \sim>128$ & $>128$ & $>128$ & I8I(87.4) & $2(0.97)$ & $24(I 1.6)$ \\
\hline Piperacillin & $\leq 16$ & $32-64$ & $\geq 128$ & $1 \sim>128$ & 128 & $>128$ & I24(59.9) & $31(14.98)$ & $52(25.1)$ \\
\hline Piperacillin-Tazobactam & $\leq 16 / 4$ & $32 / 4-64 / 4$ & $\geq 128 / 4$ & $\mid \sim>128$ & 2 & 6 & $12(5.8)$ & $7(3.4)$ & $188(90.8)$ \\
\hline Aztreonam & $\leq 4$ & 8 & $\geq 16$ & $0.125->128$ & 8 & 128 & $95(45.9)$ & $13(6.3)$ & $99(47.8)$ \\
\hline Meropenem & $\leq 1$ & 2 & $\geq 4$ & $<0.06 \sim 1$ & $<0.06$ & 0.25 & 0 & 0 & $207(100)$ \\
\hline Imipenem & $\leq 1$ & 2 & $\geq 4$ & $<0.06 \sim 2$ & 0.125 & 0.5 & 0 & $\mathrm{I}(0.48)$ & $206(99.5)$ \\
\hline Ertapenem & $\leq 0.5$ & I & $\geq 2$ & $<0.06 \sim 32$ & $<0.06$ & 0.5 & II (5.3) & $3(1.5)$ & $193(93.2)$ \\
\hline
\end{tabular}

Note: In the combinations, the concentration of tazobactam was $4 \mathrm{mg} / \mathrm{L}$ constant.

Abbreviations: MIC, minimal inhibitory concentration; S, susceptible; I, intermediate; $R$, resistant. 


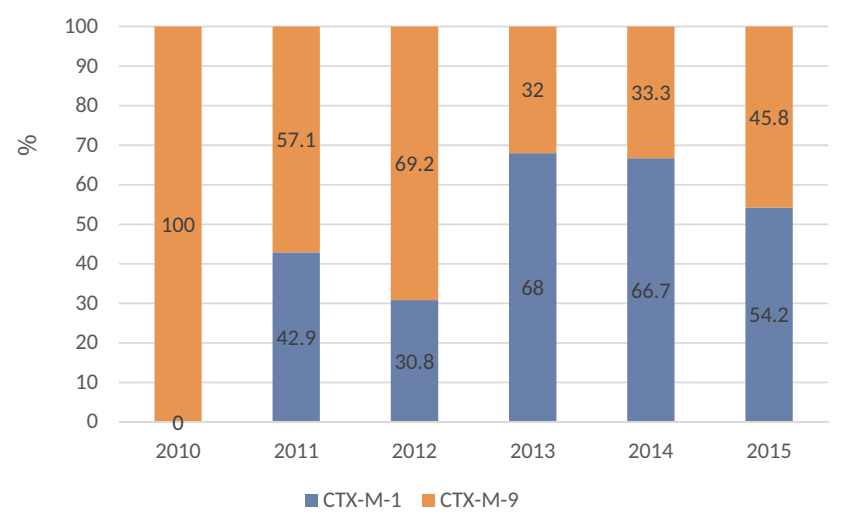

Figure 2 The distribution of ESBLs genes in ESBLs-producing Escherichia coli.

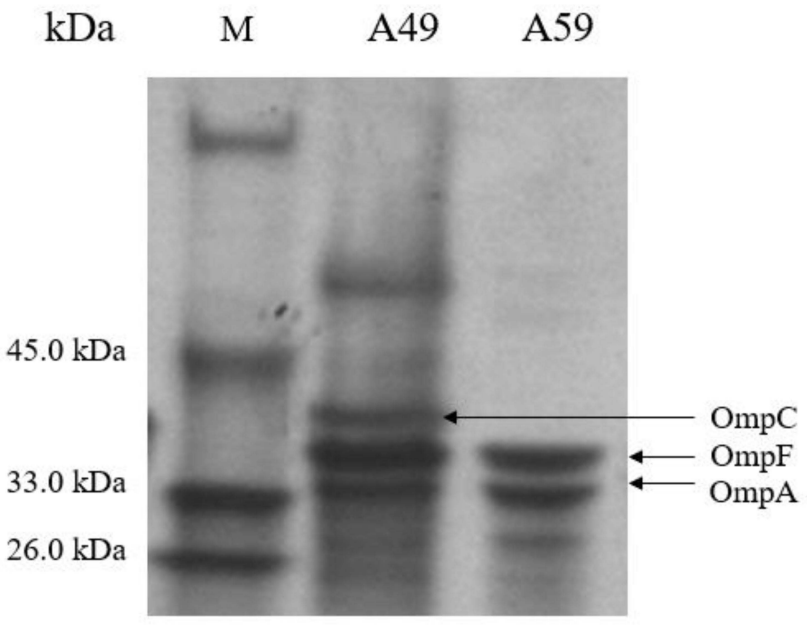

Figure 3 OMP profiles of E. coli A59 compared to its parental strain, E. coli A49. OMPs were profiled by SDS-PAGE. Lane I, marker; lane 2, E. coli A49 (control strain); lane 3, E coli A59.The horizontal arrows on the right indicate the positions of OMPs: OmpC, OmpF, and OmpA.

\section{Carbapenems' Susceptibility and Efflux Pump Inhibition Test of bla $a_{K P C}$ Positive Strains}

The MICs of KP12-100 to imipenem, meropenem, and ertapenem were $128 \mu \mathrm{g} / \mathrm{mL}, 128 \mu \mathrm{g} / \mathrm{mL}$ and $\geq 256 \mu \mathrm{g} / \mathrm{mL}$ respectively while the transformant of KP12-100 was $8 \mu \mathrm{g} / \mathrm{mL}, 4 \mu \mathrm{g} / \mathrm{mL}$ and $128 \mu \mathrm{g} / \mathrm{mL}$. The MICs of E. coli A59 to imipenem, meropenem, and ertapenem were $2 \mu \mathrm{g}$ / $\mathrm{mL}, 1 \mu \mathrm{g} / \mathrm{mL}$ and $16 \mu \mathrm{g} / \mathrm{mL}$ respectively. Efflux pump inhibitor carbonyl cyanide 3-chlorophenyl-hydrazone resulted in at least 8-fold decrease in the MIC of imipenem, meropenem and ertapenem for E. coli DH5 $\alpha$ (pKP12-100). And an 8-fold decrease in the MIC of ertapenem was observed in DH5 $\alpha-\mathrm{P} 12-100$ (Table 3).

\section{Genetic Environment of bla $a_{\mathrm{KPC}}$-Positive Strain}

Combining next-generation sequencing with a PCR mapping approach, genetic environment of bla $a_{\mathrm{KPC}}$ in $E$. coli A59 was ISKpn6-bla $a_{\mathrm{KPC}-2-I S K p n 27-I S 26}$ sharing the same core structure as that from the chromosome of ECO3385 (CP029420.1). Since bla $\mathrm{KPC}-2_{2}$ was not able to be transferred to the recipient we supposed that the bla $a_{\mathrm{KPC}}$ in E. coli A59 may be located on the chromosome (Figure 4).

\section{RT-qPCR of bla KPC Gene}

Compared with the imipenem resistant control strain, E. coli DH5a (pKP12-100), the transcription levels of

Table 3 EC-A59 Was an Ertapenem-Resistant E. coli Strain with OmpC Loss Isolated from This Study. KPI2-I00 Was a KPCProducing K. pneumoniae KPI00-12 Isolated from Huashan Hospital. DH5a-PI2-100 Was Constructed in This Study. Through the Results of Efflux Pump Inhibition Among the Three Isolates Mentioned Above Were Listed Below. Remarkable MIC Changes of ECA59 and DH5 $\alpha$-PI2-100 Were Observed in Ertapenem

\begin{tabular}{|l|l|l|l|l|l|l|}
\hline MIC (ug/mL) Strains & IMP & IMP+CCCP & MEM & MEM+CCCP & ETP & ETP+CCCP \\
\hline EC-A59 & 2 & 0.25 & 1 & 0.5 & 16 & 2 \\
DH5 $\alpha$-PI2-100 & 8 & 1 & 4 & 0.5 & 128 & 0.5 \\
KPI2-100 & 128 & 64 & 128 & 128 & $\geq 256$ & $\geq 256$ \\
\hline
\end{tabular}

Abbreviations: IMP, imipenem; MEM, meropenem; ETP, ertapenem; CCCP, carbonyl cyanide-m-chlorophenylhydrazone. 


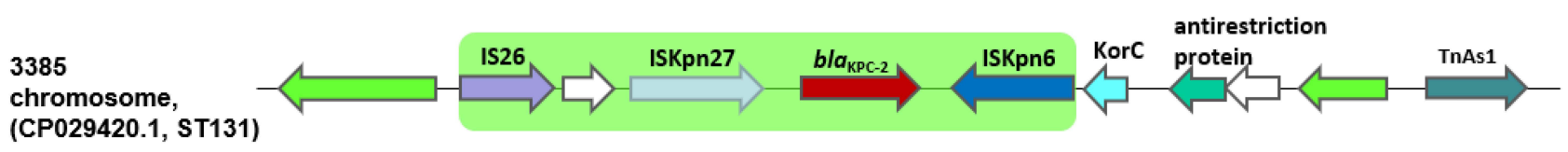

ECO-A59

(This study, ST405)

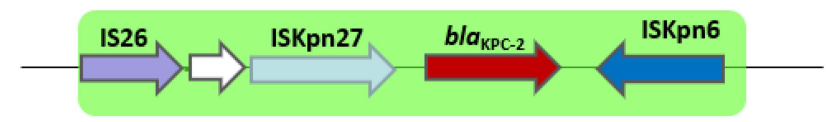

Different hypothetical proteins

Replication protein

Figure 4 Comparisons between the structures of ECO3385 and EC-A59. ISKpn6-bla $a_{\mathrm{KPC}-2}-\mathrm{ISKpn27-IS26}$ is shown in green.

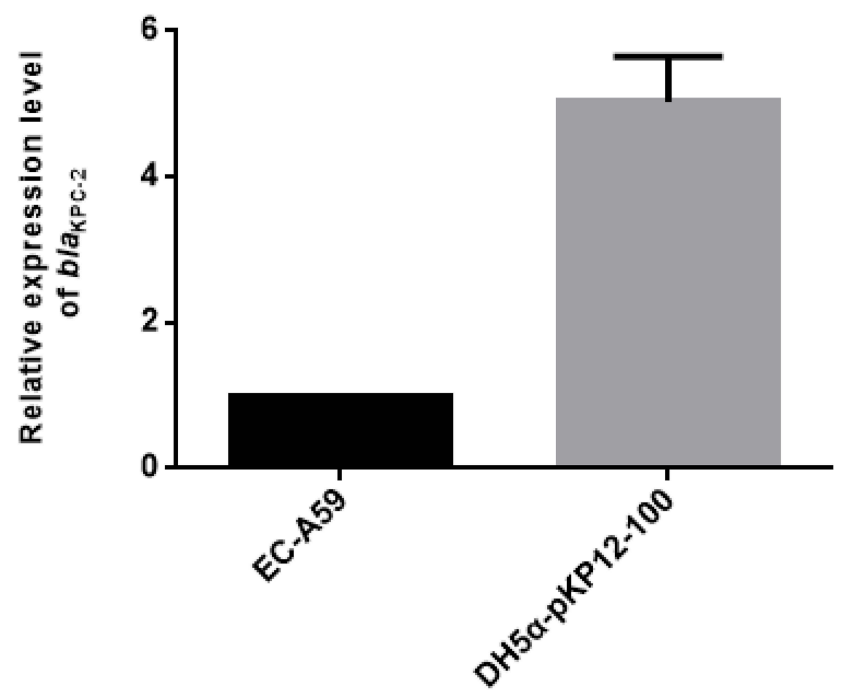

Figure 5 Transcription level of $b / a_{\mathrm{KPC}-2}$. Compared with DH5 $\alpha-\mathrm{pKPI} 2-100$, the imipenem-resistant control strain, the transcription levels of $b a_{\mathrm{KPC}-2}$ were five-fold lower in isolate $E$. coli $\mathrm{A} 59$ (EC-A59).

$b l a_{\mathrm{KPC}}$ gene were five-fold lower for isolate E. coli A59 (Figure 5). At least 280-bp sequence upstream of the bla $_{\mathrm{KPCs}}$ in the two strain was identical, see Supplementary Data 5, indicating that they shared the same promoter region of $b l a_{\mathrm{KPC}}$.

\section{Discussion}

Data from the CHINET Antimicrobial Surveillance Program showed that the proportion of E. coli in BSI pathogens is $22.2 \%$, which is a leading cause of BSI in China. The antimicrobial resistance rates of $E$. coli isolated from 35 hospitals in 2017 throughout China were as follows: $25.2 \%$ (cefepime), $25.2 \%$ (ceftazidime), $12.2 \%$ (cefoxitin), 86.5\% (ampicillin), 4.1\% (piperacillintazobactam), $1.5 \%$ (meropenem) and 1.5\% (imipenem), 2\% (ertapenem), 5.2\% (fosfomycin), 57.8\% (ciprofloxacin), 2.3\% (amikacin) (http://www.chinets.com/). In our research, the antimicrobial resistance rates were almost consistent with these data. Although all isolates were susceptible to meropenem and imipenem, there were 11 $E$. coli isolates resistant to ertapenem. According to the existing research, the expression of $\beta$-lactamases such as an AmpC $\beta$-lactamase or an ESBL combined with porin loss participated in ertapenem resistance in Enterobacteriaceae isolates. ${ }^{19}$

ESBLs are often encoded by plasmids that are transferable from strain to strain and between bacterial species. ${ }^{20,21}$

In our study, bla $a_{\mathrm{CTX}-\mathrm{M}}$ was the dominant genotype among the ESBLs-producing E. coli which is consistent with the situation in China. ${ }^{22}$ The occurrence of ESBLs is increasing. ${ }^{8}$ Data from rural Thailand showed very high rates, reaching $69.3 \%$ in 2010 . The great majority of CTX$\mathrm{M}$ alleles identified in Thailand belonged to group $9 .{ }^{23}$

Carbapenem-resistant $E$. coli is posing great challenges to human health. ${ }^{12,24}$ The plasmid-mediated horizontal transmission of carbapenemase genes is the main cause of the surge in the prevalence of CRE. NDM, one of the metallo- $\beta$-lactamases, is the predominant carbapenemase in E. coli while KPC carbapenemases are the most prevalent ones among class A carbapenemase group and found mostly on plasmids in $K$. pneumoniae. $^{15,25}$ K. pneumoniae are the predominant carriers of $b l a_{\mathrm{KPC}}$, mainly associated with the clonal group 258 (CG258) including ST258, ST11, ST340, ST512, and others. ${ }^{26,27}$ One study indicated that type I-E CRISPR-Cas system targeting the backbone regions of bla $a_{\mathrm{KPC}}$-bearing IncF plasmids influences the acquisition of $b l a_{\mathrm{KPC}}$ plasmid in K. pneumoniae. The absence of type I-E CRISPR-Cas in CG258 contributes to the dissemination of IncF epidemic resistance plasmids in this clonal complex. ${ }^{28}$ Until now, reports about KPC-producing E. coli have been rare and 
the low detection rate of bla $a_{\mathrm{KPC}}$ in $E$. coli remains obscure.

From the results of the national surveillance of CRE strains in China, it was shown that the core structure of ISKpn6-bla $a_{\mathrm{KPC}-2}$-ISKpn 27 was conservative in KPCproducing $K$. pneumoniae and $E$. coli strains. ${ }^{29}$ In this study only the chromosomes of ECO3385 (CP029420.1) and E. coli A59 shared the same core structure. In addition to the conservative sequences, they still hold another transposable element IS26, and this kind of structure was a little bit different from the previously reported pK048 (IncFIIK5) harboring non-Tn4401 elements in China. ${ }^{30}$ Whether certain divergences between $K$. pneumoniae and $E$. coli resulted in the intergeneric diversity of transposable genetic elements should be taken into consideration.

Previous research showed that KPC enzymes contribute to the carbapenem resistance in $K$. pneumoniae. ${ }^{26}$ Compared with the KP12-100, the MIC of carbapenem for its transformation strain E. coli DH5 $\alpha$ (pK12-100) had decreased at least 16-fold, which indicated the existence of other resistance mechanisms. E. coli A59 was a bla $a_{\mathrm{KPC}}$ positive strain with OmpC loss which was not resistant to meropenem and imipenem. Considering the low expression level and the failed conjugation and transformation experiments, we propose that the decreased MIC of meropenem and imipenem may be due to the low expression level of $b l a_{\mathrm{KPC}}$ located on the chromosome of E. coli A59. Only one KPC-producing E. coli was detected in this study. More strains will be included to clarify the overall detection rate of $b l a_{\mathrm{KPC}}$ in $E$. coli in the future.

\section{Ethical Statement}

The strains we used in this study were obtained from the biological sample and strains bank of the Institute of Antibiotics, Huashan Hospital, Shanghai, China. They came from normal clinical testing and were stored in the strains bank. The ethics committee of Huashan Hospital authorized our study and written informed consent was not required. This study would not do harm to rights, benefits, and health of the subjects, and the privacy and personal identity information of the subjects will not be included in this study.

\section{Acknowledgments}

We thank Leilei Wang and $\mathrm{Li}$ Ding at Institute of Antibiotics for assistance in laboratory work.

\section{Funding}

This work was supported by the National Natural Science Foundation of China (grant number 81402976 and 81673479) and Science and Technology Commission of Shanghai Municipality (grant number 18411950601).

\section{Disclosure}

The authors report no conflicts of interest in this work.

\section{References}

1. Vila J, Sáez-López E, Johnson JR, et al. Escherichia coli: an old friend with new tidings. FEMS Microbiol Rev. 2016;40(4):437-463. doi:10.1093/femsre/fuw005

2. Kern WV, Rieg S. Burden of bacterial bloodstream infection-a brief update on epidemiology and significance of multidrug-resistant pathogens. Clin Microbiol Infect. 2020;26(2):151-157. doi:10.1016/ j.cmi.2019.10.031

3. Berger J, Diab-Elschahawi M, Blacky A, et al. A matched prospective cohort study on Staphylococcus aureus and Escherichia coli bloodstream infections: extended perspectives beyond resistance. Am J Infect Control. 2010;38(10):839-845. doi:10.1016/j. ajic.2010.04.212

4. Bou-Antoun S, Davies J, Guy R, et al. Descriptive epidemiology of Escherichia coli bacteraemia in England, April 2012 to March 2014. Euro Surveill. 2016;21(35). doi:10.2807/1560-7917.ES.2016.21.3 5.30329

5. Abernethy JK, Johnson AP, Guy R, et al. Thirty day all-cause mortality in patients with Escherichia coli bacteraemia in England. Clin Microbiol Infect. 2015;21(3):251.e1-8. doi:10.1016/j.cmi.20 15.01 .001

6. Wang $\mathrm{H}$, Liu J, Huang $\mathrm{Z}$, et al. Clinical characteristics and risk factors for shock and death from E. coli bacteremia in pediatric hematological patients. J Infect Dev Ctries. 2019;13(5):365-373. doi:10.3855/jidc. 11099

7. Bush K, Bradford PA. Epidemiology of $\beta$-lactamase-producing pathogens. Clin Microbiol Rev. 2020;33(2).

8. Paterson DL, Bonomo RA. Extended-spectrum beta-lactamases: a clinical update. Clin Microbiol Rev. 2005;18(4):657-686. doi:10.1128/CMR.18.4.657-686.2005

9. Peirano G, Pitout J. Extended-spectrum $\beta$-lactamase-producing Enterobacteriaceae: update on molecular epidemiology and treatment options. Drugs. 2019;79(14):1529-1541. doi:10.1007/s40265-01901180-3

10. Pitout JD, Laupland KB. Extended-spectrum beta-lactamaseproducing Enterobacteriaceae: an emerging public-health concern. Lancet Infect Dis. 2008;8(3):159-166. doi:10.1016/S1473-3099(08) 70041-0

11. Tamma PD, Aitken SL, Bonomo RA, et al. Infectious diseases society of America antimicrobial resistant treatment guidance: gram-negative bacterial infections. Clin Infect Dis. 2020.

12. Nordmann P, Dortet L, Poirel L. Carbapenem resistance in Enterobacteriaceae: here is the storm! Trends Mol Med. 2012;18 (5):263-272. doi:10.1016/j.molmed.2012.03.003

13. Potter RF, D'Souza AW, Dantas G. The rapid spread of carbapenem-resistant Enterobacteriaceae. Drug Resist Updat. 2016;29:30-46. doi:10.1016/j.drup.2016.09.002

14. Queenan AM, Bush K. Carbapenemases: the versatile $\beta$-lactamases. Clin Microbiol Rev. 2007;20(3):440-458. doi:10.1128/CMR.00001-07

15. Munoz-Price LS, Poirel L, Bonomo RA, et al. Clinical epidemiology of the global expansion of Klebsiella pneumoniae carbapenemases. Lancet Infect Dis. 2013;13(9):785-796. doi:10.1016/S1473-3099(13) 70190-7 
16. Dallenne C, Da Costa A, Decré D, et al. Development of a set of multiplex PCR assays for the detection of genes encoding important beta-lactamases in Enterobacteriaceae. J Antimicrob Chemother. 2010;65(3):490-495. doi:10.1093/jac/dkp498

17. Portnoy DA, Wolf-Watz H, Bolin I, et al. Characterization of common virulence plasmids in Yersinia species and their role in the expression of outer membrane proteins. Infect Immun. 1984;43 (1):108-114. doi:10.1128/IAI.43.1.108-114.1984

18. Yi H, Cho Y-J, Yong D, et al. Genome sequence of Escherichia coli J53, a reference strain for genetic studies. J Bacteriol. 2012;194 (14):3742-3743. doi:10.1128/JB.00641-12

19. Chung HS, Yong D, Lee M. Mechanisms of ertapenem resistance in Enterobacteriaceae isolates in a tertiary university hospital. J Investig Med. 2016;64(5):1042-1049. doi:10.1136/jim-2016-000117

20. Rupp ME, Fey PD. Extended spectrum beta-lactamase (ESBL)-producing Enterobacteriaceae: considerations for diagnosis, prevention and drug treatment. Drugs. 2003;63(4):353-365. doi:10.2165/00003495-200363040-00002

21. Bevan ER, Jones AM, Hawkey PM. Global epidemiology of CTX-M $\beta$ lactamases: temporal and geographical shifts in genotype. $J$ Antimicrob Chemother. 2017;72(8):2145-2155. doi:10.1093/jac/dkx146

22. Hawkey PM. Prevalence and clonality of extended-spectrum $\beta$ lactamases in Asia. Clin Microbiol Infect. 2008;14(Suppl 1):159-165. doi:10.1111/j.1469-0691.2007.01855.x

23. Woerther PL, Burdet C, Chachaty E, et al. Trends in human fecal carriage of extended-spectrum $\beta$-lactamases in the community: toward the globalization of CTX-M. Clin Microbiol Rev. 2013;26 (4):744-758. doi:10.1128/CMR.00023-13
24. Bonomo RA, Burd EM, Conly J, et al. Carbapenemase-producing organisms: a global scourge. Clin Infect Dis. 2018;66(8):1290-1297. doi:10.1093/cid/cix893

25. Wu W, Feng Y, Tang G, et al. NDM metallo- $\beta$-lactamases and their bacterial producers in health care settings. Clin Microbiol Rev. 2019;32(2)

26. Chen L, Mathema B, Chavda KD, et al. Carbapenemase-producing Klebsiella pneumoniae: molecular and genetic decoding. Trends Microbiol. 2014;22(12):686-696. doi:10.1016/j.tim.2014.09.003

27. Chen L, Mathema B, Pitout JDD, et al. Epidemic Klebsiella pneumoniae ST258 is a hybrid strain. mBio. 2014;5(3):e01355-14. doi:10.1128/mBio.01355-14

28. Tang Y, Fu P, Zhou Y, et al. Absence of the type I-E CRISPR-Cas system in Klebsiella pneumoniae clonal complex 258 is associated with dissemination of IncF epidemic resistance plasmids in this clonal complex. J Antimicrob Chemother. 2020;75(4):890-895. doi:10.1093/jac/dkz538

29. Zhang R, Liu L, Zhou H, et al. Nationwide surveillance of clinical carbapenem-resistant Enterobacteriaceae (CRE) strains in China. EBioMedicine. 2017;19:98-106. doi:10.1016/j.ebiom.2017.04.032

30. Liu P, Li P, Jiang X, et al. Complete genome sequence of Klebsiella pneumoniae subsp. pneumoniae HS11286, a multidrug-resistant strain isolated from human sputum. $J$ Bacteriol. 2012;194 (7):1841-1842. doi:10.1128/JB.00043-12
Infection and Drug Resistance

\section{Publish your work in this journal}

Infection and Drug Resistance is an international, peer-reviewed openaccess journal that focuses on the optimal treatment of infection (bacterial, fungal and viral) and the development and institution of preventive strategies to minimize the development and spread of resistance. The journal is specifically concerned with the epidemiology of

\section{Dovepress}

antibiotic resistance and the mechanisms of resistance development and diffusion in both hospitals and the community. The manuscript management system is completely online and includes a very quick and fair peerreview system, which is all easy to use. Visit http://www.dovepress.com/ testimonials.php to read real quotes from published authors. 